\title{
Targeted Gene Mutation in Phytophthora spp.
}

\author{
Kurt H. Lamour, ${ }^{1}$ Ledare Finley, ${ }^{1}$ Oscar Hurtado-Gonzales, ${ }^{1}$ Daniel Gobena, ${ }^{1,2}$ Melinda Tierney, ${ }^{3}$ and \\ Harold J. G. Meijer ${ }^{2}$ \\ ${ }^{1}$ The University of Tennessee, Department of Entomology and Plant Pathology, Rm 205 Ellington Plant Science, 2431 Joe \\ Johnson Dr., Knoxville 37996, U.S.A.; ${ }^{2}$ Laboratory of Phytopathology, Plant Sciences Group, Wageningen University, \\ Binnenhaven 5, NL-6709 PD Wageningen, The Netherlands; ${ }^{3}$ The University of Tennessee and Oak Ridge National \\ Laboratory, Genome Science and Technology Graduate Program, 1060 Commerce Park, Oak Ridge 37830-8026, U.S.A.
}

Submitted 22 March 2006. Accepted 12 July 2006.

\begin{abstract}
The genus Phytophthora belongs to the oomycetes and is composed of plant pathogens. Currently, there are no strategies to mutate specific genes for members of this genus. Whole genome sequences are available or being prepared for Phytophthora sojae, $P$. ramorum, $P$. infestans, and $P$. capsici and the development of molecular biological techniques for functional genomics is encouraged. This article describes the adaptation of the reverse-genetic strategy of targeting induced local lesions in genomes (TILLING) to isolate gene-specific mutants in Phytophthora spp. A genomic library of 2,400 ethylnitrosourea (ENU) mutants of $P$. sojae was created and screened for induced point mutations in the genes encoding a necrosis-inducing protein (PsojNIP) and a Phytophthora-specific phospholipase D (PsPXTM$P L D)$. Mutations were detected in single individuals and included silent, missense, and nonsense changes. Homozygous mutant isolates carrying a potentially deleterious missense mutation in PsojNIP and a premature stop codon in PSPXTM-PLD were identified. No phenotypic effect has yet been found for the homozygous mutant of PsojNIP. For those of PSPXTM-PLD, a reduction in growth rate and an appressed mycelial growth was observed. This demonstrates the feasibility of target-selected gene disruption for Phytophthora spp. and adds an important tool for functional genomic investigation.
\end{abstract}

Additional keywords: knockout, SNP.

The genus Phytophthora comprises more than 60 species, many of which are important plant pathogens (Erwin and Ribiero 1996). They belong to the oomycetes, a group of pathogens that have evolved distinct from plants, animals, and fungi (Baldauf 2003; Keeling et al. 2005). Significant resources currently are being devoted to large-scale sequencing and research. Draft genome sequences for the soybean pathogen Phytophthora sojae and the sudden oak death pathogen $P$. ramorum became public in 2004, and genome sequences for the late-blight pathogen $P$. infestans and the vegetable pathogen $P$. capsici currently are being generated. The increasing amount of sequence data available for Phytophthora spp. prompts the development of genetic tools to explore the functions of novel

K. H. Lamour and L. Finley are co-first authors of this article.

Corresponding author: Kurt Lamour; E-mail: klamour@utk.edu genes that are identified. Direct strategies to disrupt specific genes have yet to be developed, and indirect methods that rely on random gene disruption using inserted DNA (e.g., knockout libraries with T-DNA or transposable elements) have yet to be accomplished.

Transformation of Phytophthora spp. and other oomycete species is technically challenging and has been successful for only a few species. Phytophthora spp. transformed to this point include $P$. infestans (Judelson and Michelmore 1991; Kamoun et al. 1998; Latijnhouwers and Govers 2003; van West et al. 1998), P. sojae (Judelson et al. 1993), P. palmivora (Vijn and Govers 2003), and P. parasitica (Bottin et al. 1999). Thus far, the only Pythium spp. transformed are Pythium ultimum (Vijn and Govers 2003) and Pythium aphanidermatum (Weiland 2003). The techniques utilized for Phytophthora spp. transformation include PEG-mediated transformation of protoplasts (Judelson and Michelmore 1991), electroporation of zoospores (Latijnhouwers and Govers 2003), projectile bombardment (Cvitanich and Judelson 2003), and Agrobacterium-mediated transformation (Vijn and Govers 2003). Each transformation method has its drawbacks. Producing protoplasts can be difficult and tedious, with PEG-mediated transformations yielding as few as two transformants per microgram of DNA (van West et al. 1998). Bombardment of germinated sporangia gave a higher efficiency (14 transformants/shot/microgram of DNA with $10^{6}$ sporangia) but resulted in heterokaryons (Cvitanich and Judelson 2003). Electroporation of protoplasts and zoospores has been used to transform oomycetes with varying results. Latijnhouwers and Govers (2003) reported higher efficiency of transformation with electroporation of zoospores compared with PEG-mediated transformation, whereas Blanco and Judelson (2005) found PEG-mediated transformation of protoplasts superior to electroporation. Agrobacterium tumefaciens-mediated transformation has been used successfully to transform Phytophthora infestans, P. palmivora, and Pythium ultimum and produced up to 30 transformants per $10^{7} \mathrm{zoo}-$ spores (Vijn and Govers 2003).

The ultimate goal of transformation of Phytophthora spp. has been to knockout or silence genes of interest to elucidate their function. At this time, very few genes (other than reporter genes GUS and GFP) have been silenced in Phytophthora species. In Phytophthora infestans, infl (Kamoun et al. 1998; van West et al. 1999), cdc14 (Ah Fong and Judelson 2003), Pibzpl (Blanco and Judelson 2005), Pigpbl (Latijnhouwers and Govers 2003), and Pigpal (Latijnhouwers et al. 2004) are the only genes for which stable gene silencing has been demonstrated. In $P$. para- 
sitica, the only other Phytophthora sp. in which silencing has been demonstrated, cbel was silenced by transformation (Gaulin et al. 2002). Transient silencing was demonstrated for $c d c 14$ and infl in $P$. infestans, but the extent of the silencing varied significantly over time (Whisson et al. 2005).

Here, we present a reverse-genetic strategy to recover mutants carrying amino-acid-changing lesions in specific genes for Phytophthora spp. The strategy is adapted from the targeting induced local lesions in genomes (TILLING) approach. TILLING was employed successfully in Arabidopsis, zebrafish, lotus, barley, maize, and Drosophila (Caldwell et al. 2004; Henikoff and Comai 2003; McCallum et al. 2000; Perry et al. 2003; Till et al. 2003; Wienholds et al. 2003; Winkler et al. 2005). The process involves the development and screening of a chemically mutagenized population to isolate individuals carrying induced mutations within a gene of interest. We describe the details of TILLING as it has been adapted to $P$. sojae, present the initial screening for mutations in two gene tar- gets (PsojNIP and PsPXTM-PLD), and present the preliminary characterization of oospore progeny homozygous for a knockout mutation in PSPXTM-PLD.

\section{RESULTS AND DISCUSSION}

The TILLING procedure in Phytophthora spp.

An overview of the TILLING process which is modified for Phytophthora spp., starting with the mutagenesis of swimming zoospore to the final characterization of isolates carrying homozygous mutations of a gene of interest, is depicted in Figure 1. The key steps are i) mutagenesis of Phytophthora zoospores and the conservation of the mutant library and isolation of their genomic DNA (Fig. 1A and B), ii) polymerase chain reaction (PCR) amplification of genes of interest and subsequent screening for induced mutations (Fig. 1C), and, finally iii) production of selfed progeny to obtain homozygous mutants for the gene of interest (Fig. 1D).
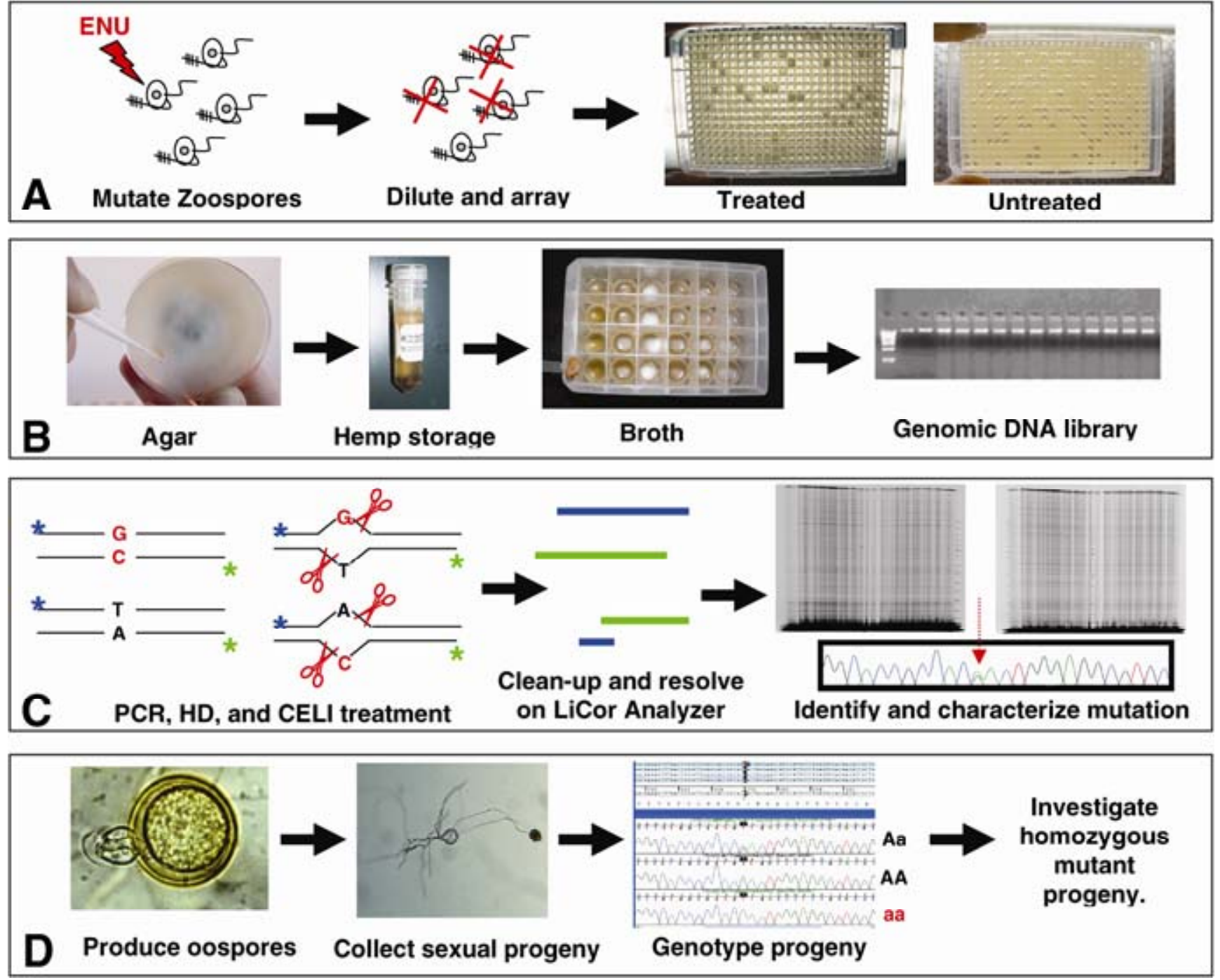

Fig. 1. Overview of the targeting induced local lesions in genomes (TILLING) process for Phytophthora. A, Swimming zoospores are treated with ethylnitrosourea (ENU) and the surviving spores are arrayed into 384-well plates. B, Individual mutant colonies are transferred to solid V8 juice agar, assigned a unique identifier, transferred to long-term hemp seed storage, and transferred to 24-well broth plates for mycelium production. Genomic DNA is extracted from the mycelium to create a genomic DNA library. $\mathbf{C}$, The genomic DNA library is screened to identify mutants carrying induced mutations within specific genes. Screening is accomplished by i) amplifying a $1 \mathrm{~kb}$ target with 700 and $800 \mathrm{~nm}$ IRD-labeled forward and reverse primers, respectively; ii) heating and cooling the polymerase chain reaction (PCR) products to form heteroduplexes (HD); iii) treating the resulting HDs with the single-strand-specific nuclease CEL I which cuts $3^{\prime}$ of single base mismatches; iv) resolving the treated products on a LiCor sequencing machine; v) identifying isolates carrying induced point mutations; and (vi) characterizing the mutations. D, Isolates carrying what appear to be disruptive mutations are taken through the sexual stage to recover recombinant progeny and the homozygous mutant genotypes are assayed to determine the impact of the induced mutation. 


\section{Mutant library construction.}

Mutants were derived from $P$. sojae strain P6497 (Forster et al. 1994) also used for the genome sequencing project (Jiang et al. 2006; Tyler et al. 2006). To deduce the impact of chemical mutagenesis with ethylnitrosourea (ENU), lethality was determined for a range of concentrations. Exposure of the zoospores to doses of ENU ranging from 0.85 to $8.5 \mathrm{mM}$ ENU resulted in a concentration-dependent increase of lethality (Fig. 2). A limited number (between 384 and 1,000 mutants) of zoospores for each ENU concentration was screened to identify a mutation rate of one mutation per approximately $200 \mathrm{~kb}$ (two 96well plates). Recovery of at least one mutation within one $1-\mathrm{kb}$ gene target per 192 individuals required a concentration of 8.5 $\mathrm{mM}$ ENU, which consistently resulted in $>90 \%$ lethality of the zoospores (Figs. 1A and 2). Therefore, this concentration was chosen for the construction of a mutant library of 2,400 individuals (Fig. 1B).

\section{Target selection and library screening.}

Using the TILLING strategy, any segment of the genome that can be amplified as a single PCR product can be screened for induced point mutations. To determine whether the TILLING strategy is functional for $P$. sojae, two genes were chosen: the $P$. sojae necrosis-inducing protein-encoding gene PsojNIP (Qutob et al. 2002) and a Phytophthora-specific phospholipase D gene (PsPXTM-PLD), homologous to the PiPLDl gene as described for $P$. infestans (Meijer et al. 2005). One of the key criteria was that developed primers amplified a clear, single, approximately $1-\mathrm{kb}$ PCR product. The amplicon sizes were 994 and 1,004 bp for PsojNIP and PXTM-PLD, respectively. For the two targets, either the entire gene (PsojNIP) or a portion of the coding region (PXTM-PLD) was amplified. In the latter case, the TILLING targeted part spanned the region encoding the first catalytic HKD motif and the phosphatidylinositol 4,5-bisphosphate [PI(4,5) $\left.\mathrm{P}_{2}\right]$-binding domain (Fig. 3).

Screens were conducted on unpooled DNA, derived directly from ENU-exposed isolates. A typical set of gel images is shown in Figure 4. In other organisms that have TILLING initiatives, genomic DNA from multiple individuals often are pooled to reduce the number of gels which must be run (Colbert et al. 2001). Based on the level of signal for both the full- length and truncated PCR products, pooling between two- and fourfold might be possible.

\section{Characteristics of induced mutations.}

For PsojNIP, 10 induced mutations were detected in a screen comprising 1,824 mutants. The PsojNIP target amplicon is 994 bases and the frequency of induced mutation is 1 per $181 \mathrm{~kb}$ of sequence. Two of the mutations are silent, one is upstream of the coding sequence, and seven induce an amino acid substitution (Fig. 5; Table 1). Highly conserved residues within PsojNIP have been identified based upon comparison with other members of this large and diverse gene family, known as the Nep1-like proteins (NLPs). The NLPs are known to occur in oomycetes, fungi, and bacteria and trigger cell death and defense in plants (Gijzen and Nurnberger 2006). The most conserved region of all NLPs corresponds to a hepta-peptide motif in the central area of the proteins with the sequence "GHRHDWE" (Gijzen and Nurnberger 2006). In two of the PsojNIP mutants identified, K1857 (D124N) and K3489 (W125R), residues within this motif are substituted (Fig. 5). Other TILLING mutants carry substitutions in amino acids that are less conserved, but nonetheless may affect the activity of the protein (Table 1).

For $P X T M-P L D, 13$ mutations were found in a screen of 1,344 mutants. The PXTM-PLD target amplicon is 1,004 bases and the frequency of induced mutation is 1 per $104 \mathrm{~kb}$ of sequence. Three of the induced changes are silent; nine mutations results in an amino acid substitution, and one caused a premature stop codon (Fig. 3; Table 2). None of the amino acid changes was located in the catalytic motif. Alignment with other PXTM-PLDs showed that most of the substitutions are localized in conserved amino acids (Fig. 3). However, when PXPH-PLDs were taken into account, none of the substituted amino acids was strictly conserved. Therefore, the impact of mutations was based mostly on the type of amino acid substitution (Table 2). An attractive candidate mutation for further research is found in $\mathrm{K} 2870$; the mutation causes a premature stop codon positioned at the end of the $\mathrm{PI}(4,5) \mathrm{P}_{2}$-binding domain, behind the first catalytic HKD motif. Therefore, the resulting truncated protein is expected to be nonfunctional (Table 2).

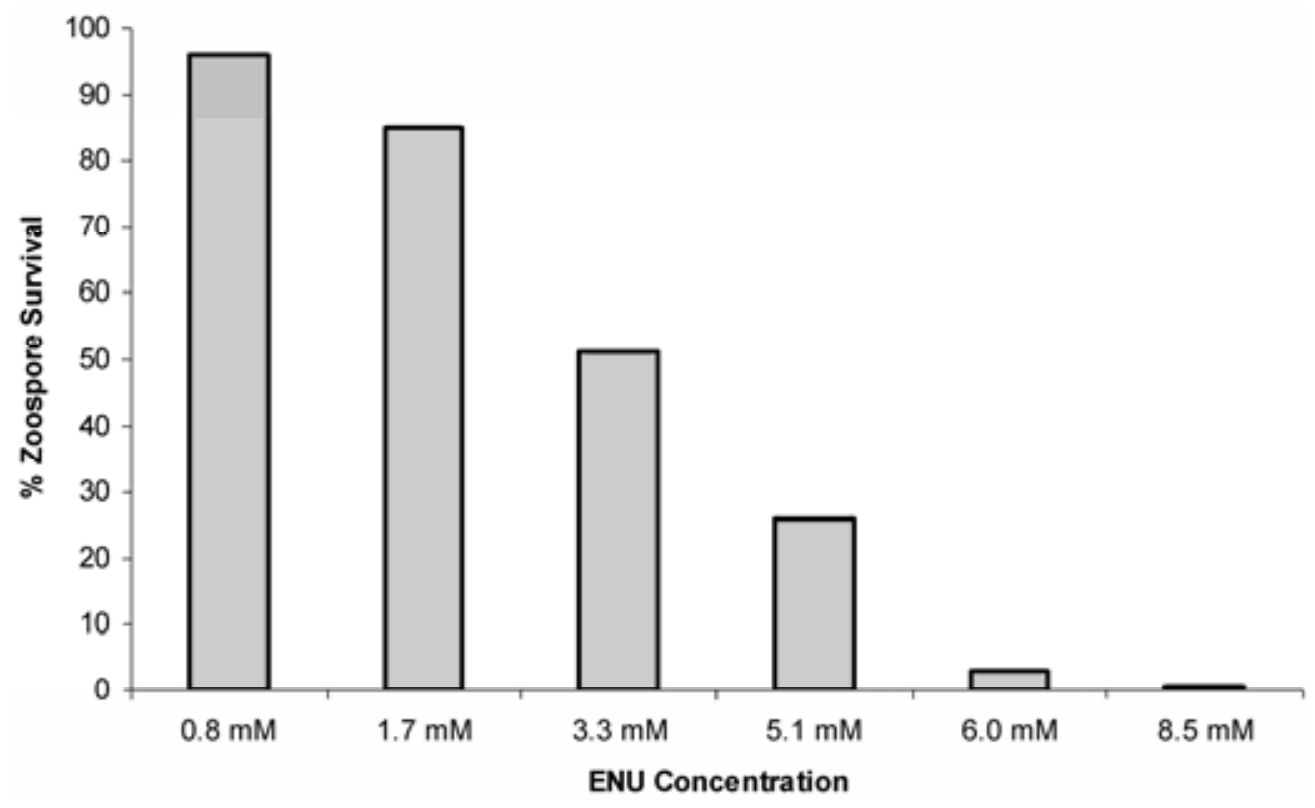

Fig. 2. Response of Phytophthora sojae zoospores to treatment with the chemical mutagen ethylnitrosourea (ENU). The percentage of survival, as determined by mycelial growth, is depicted against the concentration of ENU that was used to treat the zoospores. 


\section{Recombinant mutant progeny.}

Because screening was performed on zoospore-derived isolates, all of the induced mutations are in the heterozygous state. This differs from other organisms (e.g., Arabidopsis), where the TILLING population has been through one round of sexual recombination and individuals carry induced mutations in the heterozygous or homozygous state (Caldwell et al. 2004; Henikoff and Comai 2003; McCallum et al. 2000; Perry et al. 2003; Till et al. 2003; Wienholds et al. 2003; Winkler et al. 2005). Therefore, two mutant isolates, K1857 (PsojNIP) and K2870 (PsPXTM-PLD), one for each of the gene targets, were studied in more detail.

$P$. sojae is self fertile and produces sexual oospores in single culture. Eighty-two oospore progeny were collected from isolate K1857 and the allelic state was tested using an allele-specific real-time PCR single-nucleotide amplified polymorphism (SNAP) strategy (Fig. 6). The progeny of K1857 had the following genotypes: 15 homozygous wild types, 56 heterozygous, and 11 homozygous mutant progeny. A $\chi^{2}$ analysis indicated that our observed values differed significantly from those expected with Mendelian inheritance $\left(\chi^{2}=11.35,2 \mathrm{df}\right)$. Colony morphology and growth rates for the homo- and heterozygous progeny classes were not markedly different and preliminary studies indicated that the mutant progeny were able to cause infection on soybean (details not reported).

For isolate K2870, 22 oospore progeny were collected. The allelic state was tested by direct sequencing because it was not possible to design reliable allele specific primers for the PsPXTM-PLD knockout mutation. The progeny included 2 homozygous wild types, 16 heterozygous, and 3 homozygous mutants. One of the heterozygote isolates, LT2096, appeared to make more oospores than its parent strain. To test whether it was possible to recover a higher number of homozygous mutants' oospore progeny, we also recovered an additional set of 56 oo- spore progeny from this isolate. The recovered progeny set of 56 oospores was composed of 3 homozygous wild types, 51 heterozygous, and 2 homozygous mutants. Similar to the ratios observed for the PsojNIP mutation, there was an excess of the heterozygous progeny class, and both progeny sets were significantly different from the ratios expected for simple Mendelian inheritance. Some of the possible reasons for the distorted ratios are that homozygous mutant oospore progeny suffer from the lack of a functional PSPXTM-PLD, there is a leak-through of the parental heterozygous mutant, or that another unidentified mutation is responsible for the unequal numbers.

All 73 of the PXTM-PLD wild-type and heterozygous progeny had normal aerial mycelium morphologically similar to the original parental nonmutant parent isolate and all but four had growth rates similar to the parent type (Fig. 7). In contrast, the five homothallic knockout isolates all had slow growth rates and distinctive appressed mycelium. It remains to be deduced in detail how the growth defect is accomplished via mutation in the PXTM-PLD gene. However, studies in plants and yeast might point to its involvement in cellular dynamics (Dhonukshe et al. 2003; Ella et al. 1996; Gardiner et al. 2001; Rudge et al. 1998; Waksman et al. 1996; Zouwail et al. 2005). Future work on characterizing the mutants will center on PXTM-PLD activity and function.

\section{Concluding remarks.}

This is the first report of a targeted strategy to mutate specific genes in Phytophthora spp. The strengths of this approach are its broad applicability and the ability to recover allelic as well as knockout mutations. A weakness is the effect of other mutations that occur during the process of mutagenesis. For each individual in this $P$. sojae population, it is estimated that one point mutation is present every 100 to $200 \mathrm{~kb}$. With a genome size of approximately 100 million bases, this means that there are 500 to

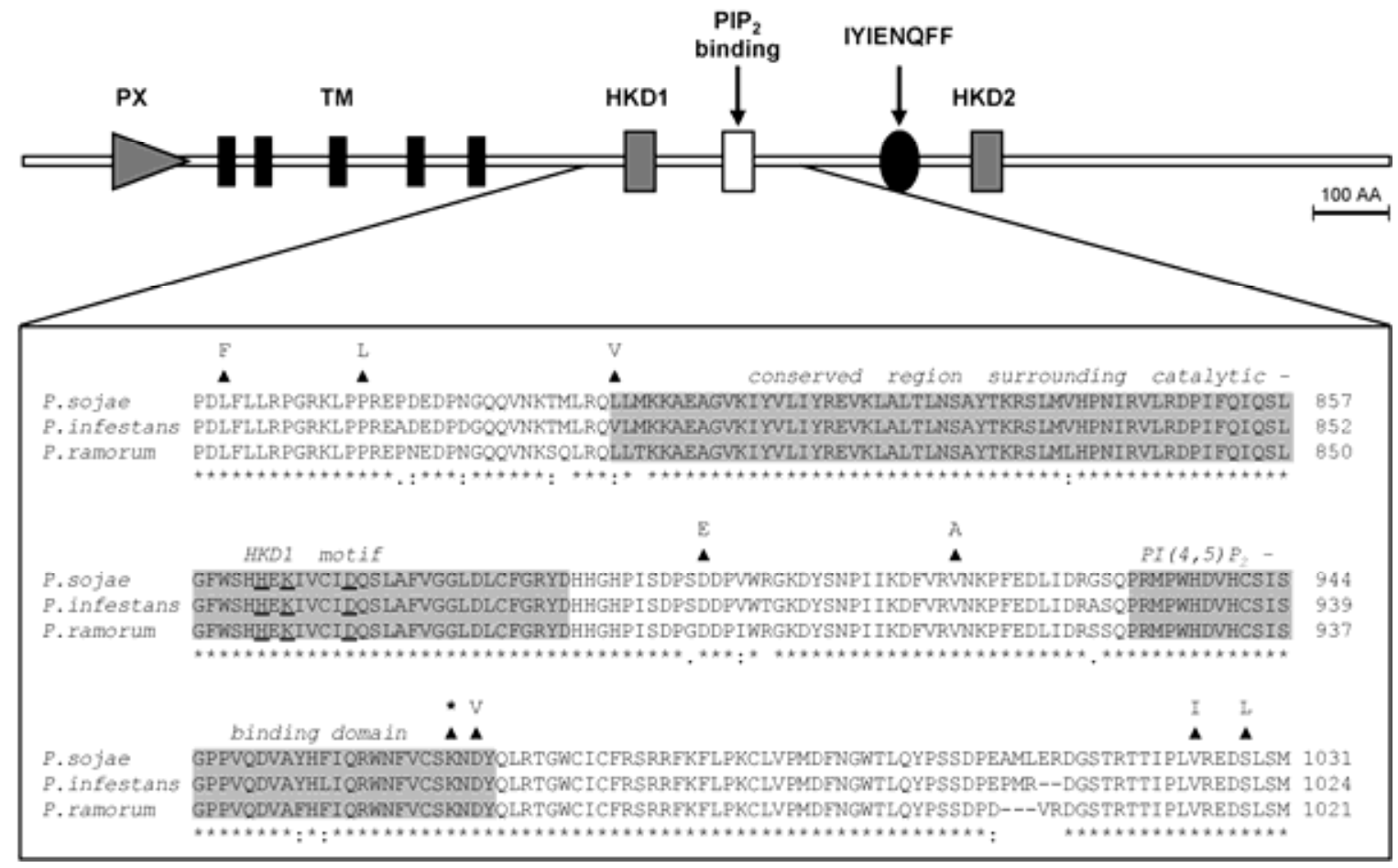

Fig. 3. Schematic representation of the domain structure of the Phytophthora sojae PXTM-PLD protein (PLD_163010). The bar indicates the size of 100 amino acids. The enlarged area in the box has been targeted for targeting induced local lesions in genomes (TILLING). The region is aligned on amino acid level with PXTM-PLD proteins from other Phytophthora spp.: P. infestans, PiPLD1, AY929154; and P. ramorum, PLD_101442. The conserved region around the HKD motif and the $\mathrm{PI}(4,5) \mathrm{P}_{2}$-binding domain are shaded. The HKD motif is underlined. Numbers indicate the amino acid position for each protein. Amino acid changes in P. sojae PXTM-PLD that were generated by TILLING are shown with an up-pointing arrowhead over the exact residue. The asterisk indicates the full stop. 
1,000 mutations per individual. The predicted 20,000 genes make up an estimated $40 \%$ of the total genome size; therefore, the chance for additional missense or nonsense mutations is clearly a factor. Multiple recombinant mutant progeny homozygous for the induced change must carry the functional change ascribed to the induced mutation (e.g., the phenotype is fully linked to the mutation). Although the number of homozygous mutants recovered thus far is limited, it appears that the mutants carrying the knockout mutation for the PSPXTM-PLD gene have a distinctly altered mycelial growth form compared with the other genotype classes. Even in this case, where the phenotype is strictly inherited with an induced mutation, it still is possible that a tightly linked undetected functional mutation is actually responsible for the observed impact. The only way to be certain is to study another mutant carrying an independent deleterious mutation and confirm the observed results.

Another factor that may impact the results from a TILLING screen strategy is genetic redundancy. The PsojNIP gene is only one member of the NLP family in $P$. sojae that comprises 58 predicted genes with sustained sequence similarity. However, closer examination indicated that at least half of the NLPs are pseudogenes and only three genes (PsojNIP and two others) are represented by expressed sequence tag hits. Two NLP genes previously were analyzed for expression but no transcripts were detected (Qutob et al. 2002). Analysis of PsojNIP also has shown that this gene is specifically expressed during late stages of plant infection (Jiang et al. 2006; Moy et al. 2004; Qutob et al. 2002). Thus, despite the NLPs composing one of the largest gene families known in $P$. sojae, the evidence suggests that many of these genes either are not expressed or differentially expressed. This increases the chance that PsojNIP mutants display an as-yet-undetected phenotype. It also underscores the importance of prior genomic investigation to determine the suitability of a gene target for TILLING.

Overall, it appears that TILLING provides a valuable tool for elucidation of gene functions in Phytophthora spp. Improvements in SNP (single nucleotide polymorphism) detection technology and in techniques related specifically to ma- nipulating Phytophthora spp. through the sexual stage will greatly improve our current efficiency. Furthermore, this approach should be readily adaptable to any fungal or fungal-like organism that can be grown in broth culture and that has a spore stage amendable to chemical mutagenesis.

\section{MATERIALS AND METHODS}

\section{Strains and growth conditions.}

P. sojae strain P6497 (University of California, Riverside, U.S.A.) (Forster et al. 1994), was grown on V8 juice agar (unfiltered) amended with PARP (pimaricin, 25 ppm; ampicillin, $100 \mathrm{ppm}$; rifampicin, $25 \mathrm{ppm}$; and pentachloronitrobenzene, $25 \mathrm{ppm}$ ) for 9 days at room temperature. Sporangial development was induced by repeated washing of the mycelial colonies (Morris et al. 1998; Morris and Ward 1992) and zoospore release was induced by incubating the plates overnight with sterile water. Zoospores were harvested by filtering through two layers of sterile Kimwipe (Kimberly-Clarke Inc., Roswell, GA, U.S.A.) and the number of zoospores was determined by microscope counting.

\section{Mutagenesis.}

ENU (Sigma-Aldrich, Inc., St. Louis) was administered as an $85 \mathrm{mM}$ stock solution in dimethylsulfoxide (DMSO) and stored until usage at $-20^{\circ} \mathrm{C}$. Mutagenesis was accomplished by incubating 5 or $10 \mathrm{ml}$ of swimming zoospores at a zoospore concentration of 10 zoospores/ $\mu \mathrm{l}$ at a final concentration of 8.5 $\mathrm{mM}$ ENU for $1 \mathrm{~h}$ on a Minilab Roller shaker (Labnet Int., Edison, NJ, U.S.A.). The mutagenesis process was halted by addition of an equal volume of $6 \%$ sodium thiosulfate and immedi ately diluted with clarified PARP V8 broth to 1 zoospore/10 $\mu \mathrm{l}$. Aliquots $(10 \mu \mathrm{l})$ of diluted zoospore culture then were arrayed into 384-well plates preloaded with $50 \mu \mathrm{l}$ of V8-PARP broth and incubated for 7 days at room temperature (approximately $23^{\circ} \mathrm{C}$ ) under laboratory lighting. Parallel control reactions were performed in which the ENU treatment was replaced with water. Percent lethality was determined as the ratio between the

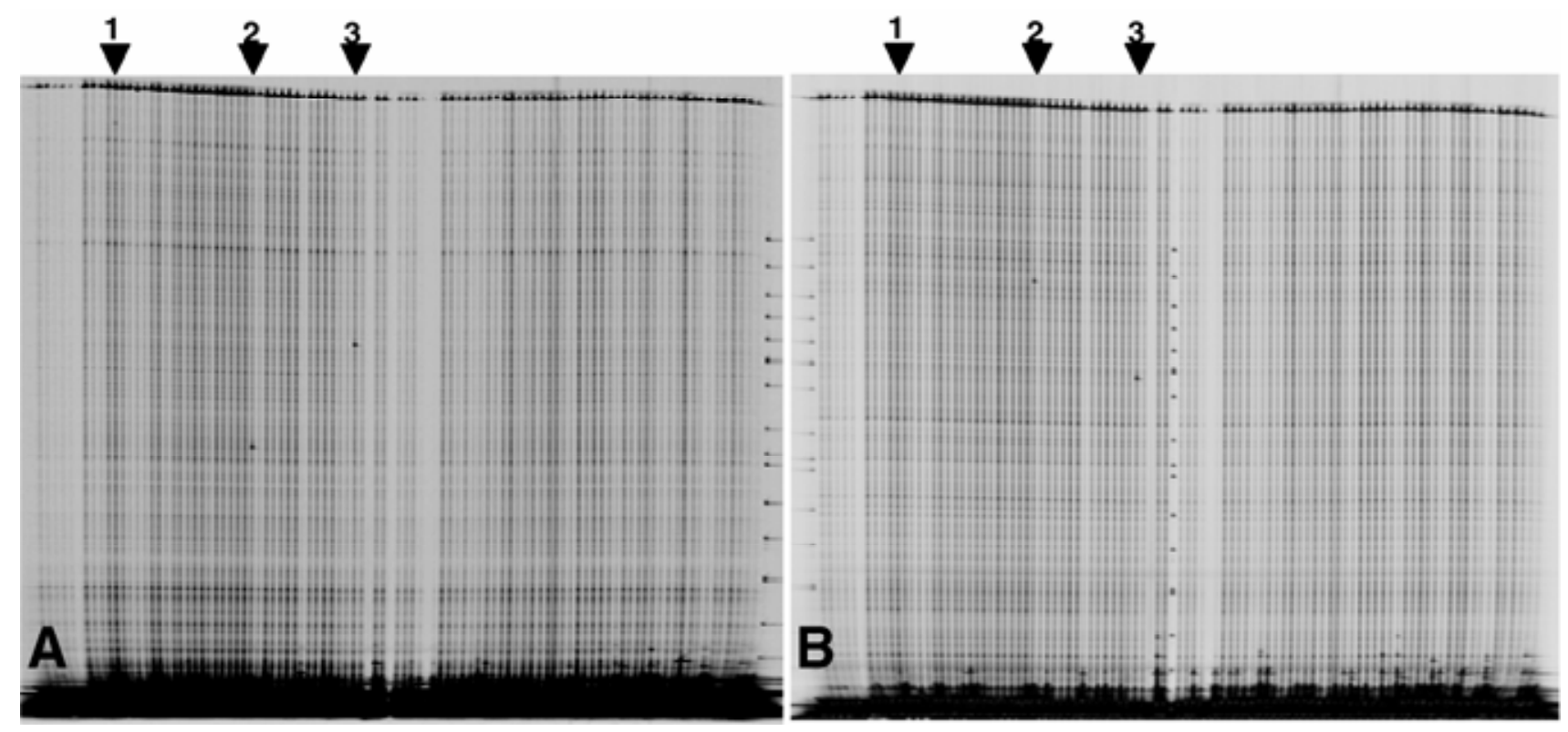

Fig. 4. Representative LiCor gel images showing CEL I-treated polymerase chain reaction (PCR) products for a 1-kb portion $P X T M-P L D$ gene in $P$ hytophthora sojae. The full-length PCR product is visible as a dark line at the top of each of the 96 wells. Amplicons harboring induced mutations are cut into two fragments labeled with either the 700- or 800-nm IRdye. A, The 800-nm gel image and the black arrows point to lanes with three novel fragments of approximately 900 nucleotides (nt) (1), $360 \mathrm{nt}$ (2), and $515 \mathrm{nt}$ (3) in length. B, The 700-nm image of the same gel and the complementary fragments are clearly visible for the number 2 and 3 mutations and not visible for the much smaller (approximately 100-nt) fragment of mutation 1 . The ladder has fragments of $700,650,600,565,530,500,495,460,400,364,350,300,255,204,200,145,100$, and $50 \mathrm{nt}$ 
colonies from plates with ENU-treated zoospores and the number of colonies in the control plates.

\section{Construction of ENU-treated Phytophthora library.}

Colonies derived from ENU-treated zoospores were transferred individually to $60-\mathrm{mm}$ V8-PARP agar plates. The isolates were grown for at least 3 days at room temperature and divided thereafter for long-term storage or for mycelial growth to isolate genomic DNA. For long-term storage, two 7-mm plugs of actively expanding mycelium were transferred to 2-ml screw-cap tubes containing two sterile hemp seed and $1 \mathrm{ml}$ of sterile MilliQ water. For mycelium production, wefts of aerial mycelium were transferred to 4 wells of a 24-well deep-well plate containing $1 \mathrm{ml}$ of V8-PARP broth per well. The 24-well plates were covered with AeraSeal rayon breathable tape (PGC Scientifics, Frederick, MA, U.S.A.) and incubated at room temperature without agitation for 7 days. The mycelial mats for each isolate were combined and placed into individual wells of a 2-ml 96-well plate preloaded with three 3-mm glass balls and lyophilized for $48 \mathrm{~h}$ in a Labconco stoppering tray dryer system (Labconco Corp., Kansas City, MO, U.S.A.) with the incubation chamber set to $0^{\circ} \mathrm{C}$ for the first $24 \mathrm{~h}$ and $24^{\circ} \mathrm{C}$ for the second $24 \mathrm{~h}$. The dried mycelium then was disrupted to a fine powder using a Mixer Mill MM 300 (Retsch Inc., Newton, PA, U.S.A.). The genomic DNA was extracted from the powdered mycelium as reported previously (Lamour and Finley 2006).

\section{Primer design.}

Primers for TILLING were designed using the codons optimized to detect deleterious lesions (CODDLE) primer design program. In total, five sets of primers automatically were designed for each of the two target genes (PsojNIP and PXTM$P L D)$. Nonfluorescent primers were tested to determine which primers amplified a single product from $P$. sojae genomic DNA. Once a set of desired primers was identified, IRDye700 and IRDye800 dye-labeled primers were synthesized and used to screen the $P$. sojae TILLING library. For screening PsojNIP, the primer sequences PsojNIP-F (IRD700-GATTGCCCCGCC TTTTCTTGCTTA) and PsojNIP-R (IRD800-GCGCGATTAG CGAACGAGATTCAC) were used. The primer pair PsPXTM$P L D-F$ (IRD700-GCCATCTCCAACGCCAAGTACGAG and $P s P X T M-P L D$-R (IRD800-GCACGCAACACTTCACCATCG TCT) was used for PSPXTM-PLD screening.

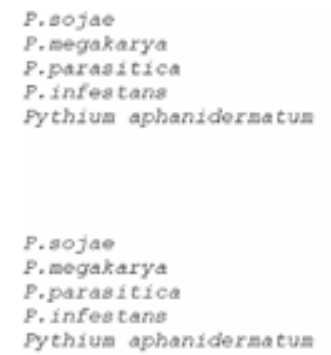

DU--LRPALLATLASFAYVSASVTMIDQVVPETQP-TPTTALQQAVKYKPQTYT OV--LRVIIFAGEAYLSGVQAAVIDHDQVVPEAQP-TPNTTVQSVALKE KPQIYINDGCH 57 MD--VLTYLIAAAVSLAVVQADVISHDAVVPFAQP-TATTTEQKAGVKFKPQIHISNGCH S? ND--ILQLFASAAAALTVAHADVISHDAVI PFAQPTTTTTTEQKAGIKF KPQTHI SWGCH $5:$ MVRFV SALLLANUGVLASTALAVINHDAVPVWPQP-EPADATQALAVRFKPQLDVVNGCQ 59

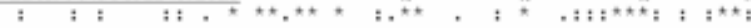

PYPAVDNWGHTSGGLNPTGSESAGCKGSGYGTQIYGRAVKYQGVYAFMYWYMPKDETLT 117 EYPAVDSDGNTSGGLAPTGSESAGCKGSGYGSQVYGRAVECDGVYAMYYWYMPKDETLP 117 PYPAVDANGNTSGGLKPTGSSSAGCKGSGYGSOVYGRVATYNGVYAIMYSWYY PKDSPVT 117 PYPAVDADGNTSGGLNPTGSSSAGCKGSGYGSQIYGRVATYNGVFAIMYSWYF PKDSPLT 118 PYPAVDRZ

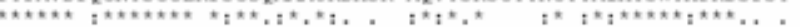

P.sojae
P. mogakarya
P.parasitica
P.infestans
Pychium aphanidermatum

$\sum_{G L}$ $\boldsymbol{\Lambda}$

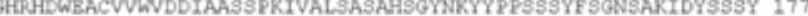
GLSH HWEACVVWIDSLTSQN--IAALSASAHSGYNTYYPPSSSYFDGDSAKIGYSSSY $17 \%$

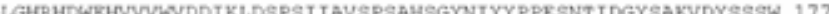

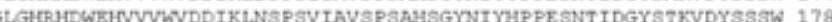
GIGHRMDWENVVVWLDNAASAN--IVALSASAHSGYKKSF PADKSYLDGITAKISYKSTW 176

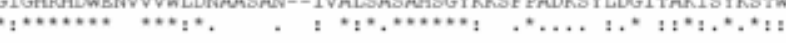

Fig. 5. Protein alignment of homologous necrosis-inducing proteins (NIPs) from different Phytophthora and Pythium spp. Mutated amino acids identified by targeting induced local lesions in genomes (TILLING) are shown with an up-pointing arrowhead over the exact residue in the NIP from Phytophthora sojae. Underlined residues correspond to the predicted signal peptide. P. sojae: AAM48170, P. parasitica: AAK19753, P. infestans: AAK25828, P. megakarya: AAX12401, Pythium aphanidermatum: AAD53944.

Table 1. Summary of induced changes for PsojNIP a

\begin{tabular}{|c|c|c|c|c|c|c|}
\hline Position $^{b}$ & Isolate & $\begin{array}{c}\text { Nucleotide } \\
\text { change }\end{array}$ & $\begin{array}{c}\text { Amino acid } \\
\text { change }\end{array}$ & Amino acid property change ch $^{c}$ & $\begin{array}{c}\text { Substitution } \\
\text { preference }^{c}\end{array}$ & $\begin{array}{c}\text { Conserved in } \\
\text { Phytophthora sp. }\end{array}$ \\
\hline-19 & K2141 & $\mathrm{A} \rightarrow \mathrm{G}$ & Promoter region & NA & NA & NA \\
\hline 258 & K2338 & $\mathrm{C} \rightarrow \mathrm{T}$ & $\mathrm{G}$ to $\mathrm{G}$ & NA & NA & NA \\
\hline 265 & $\mathrm{~K} 2302$ & $\mathrm{G} \rightarrow \mathrm{A}$ & $\mathrm{Q}$ to $\mathrm{Q}$ & NA & NA & NA \\
\hline 284 & K3177 & $\mathrm{C} \rightarrow \mathrm{T}$ & A to $\mathrm{V}$ & Nonaliphatic and very small to aliphatic & Neutral & No \\
\hline 353 & K3655 & $\mathrm{G} \rightarrow \mathrm{A}$ & $\mathrm{G}$ to $\mathrm{E}$ & Very small, hydrophobic to polar, negative charged & Disfavored & No \\
\hline 370 & K1857 & $\mathrm{A} \rightarrow \mathrm{G}$ & $\mathrm{D}$ to $\mathrm{N}$ & Negative charge to small polar & Favored & Yes \\
\hline 373 & K3489 & $\mathrm{T} \rightarrow \mathrm{A}$ & $\mathrm{W}$ to $\mathrm{R}$ & Aromatic to nonhydrophobic positive charge & Disfavored & Yes \\
\hline 424 & K2533 & $\mathrm{A} \rightarrow \mathrm{G}$ & I to $\mathrm{V}$ & Aliphatic to small aliphatic & Favored & No \\
\hline 512 & K2690 & $\mathrm{T} \rightarrow \mathrm{G}$ & I to $\mathrm{S}$ & Aliphatic to polar & Disfavored & No \\
\hline 640 & K2973 & $\mathrm{G} \rightarrow \mathrm{C}$ & $\mathrm{D}$ to $\mathrm{H}$ & Small negative charge to aromatic positive charge & Disfavored & No \\
\hline
\end{tabular}

${ }^{\mathrm{a}} \mathrm{NA}=$ not applicable.

${ }^{\mathrm{b}}$ Nucleotide position from the predicted start codon of Phytophthora sojae ID 130122 in the VBI microbial database.

c According to Betts and Russell (2003). 
Fluorescent target amplification and nuclease treatment.

The DNA from the mutant library was diluted from 1:100 to $1: 150$ in $10 \mathrm{mM}$ Tris $(\mathrm{pH} 8.0)$ to a final concentration of between 0.01 and $0.05 \mathrm{ng} / \mu \mathrm{l}$. The individual PCR reactions contained $50 \mathrm{mM} \mathrm{KCl}, 10 \mathrm{mM}$ Tris (pH 8.3), $0.4 \mathrm{mM}$ dNTP, 0.12 $\mu \mathrm{M}$ IRDye700-labeled forward primer, $0.08 \mu \mathrm{M}$ unlabeled forward primer, $0.16 \mu \mathrm{M}$ IRDye800-labeled reverse primer, 0.04 $\mu \mathrm{M}$ unlabeled reverse primer, 0.1875 units of MasterTaq polymerase (Eppendorf, Westbury, NY, U.S.A.), and $5 \mu \mathrm{l}$ of diluted genomic DNA (final concentration of between 0.05 and 0.25 $\mathrm{ng} / \mu \mathrm{l})$ in a final volume of $10 \mu \mathrm{l}$. The PCR cycling conditions were as follows: $95^{\circ} \mathrm{C}$ for $2 \mathrm{~min}$, loop $1\left(8\right.$ cycles of $94^{\circ} \mathrm{C}$ for $20 \mathrm{~s}, 73^{\circ} \mathrm{C}$ decreasing $-1^{\circ} \mathrm{C}$ per cycle for $30 \mathrm{~s}, 72^{\circ} \mathrm{C}$ for $1 \mathrm{~min}$, ramping to $72^{\circ} \mathrm{C}$ at $\left.0.5^{\circ} \mathrm{C} / \mathrm{s}\right)$, loop $2\left(45\right.$ cycles of $94^{\circ} \mathrm{C}$ for $20 \mathrm{~s}$, $65^{\circ} \mathrm{C}$ for $30 \mathrm{~s}, 72^{\circ} \mathrm{C}$ for $1 \mathrm{~min}$, ramping to $72^{\circ} \mathrm{C}$ at $\left.0.5^{\circ} \mathrm{C} / \mathrm{sec}\right)$, $72^{\circ} \mathrm{C}$ for $5 \mathrm{~min}, 99^{\circ} \mathrm{C}$ for $10 \mathrm{~min}$, and a final heteroduplex formation loop $\left(70^{\circ} \mathrm{C}\right.$ for $20 \mathrm{~s}$, decreasing $-0.3^{\circ} \mathrm{C} /$ cycle for $70 \mathrm{cy}-$ cles) (Colbert et al. 2001). The PCR reactions were performed using an MJ Research DNA Engine Dyad and Disciple (MJ Research, Hercules, CA, U.S.A.) thermal cycler system.

The PCR products were digested with a member of the $S_{1}$ nuclease family (designated CEL I) purified from celery (Apium graveolens). CEL I cleaves mismatches on either strand on the $3^{\prime}$ side of a single base mismatch in heteroduplex DNA. Enzyme purification was carried out according to a modification of the protocol of Oleykowski and associates (1998) and Yang and associates (2000) described by Till and associates (2003). Appropriate concentrations of CEL I for mismatch cleavage were determined by testing enzyme dilutions on PCR amplicons containing known heterozygous bases. CEL I digestions contained the following components in a $20-\mu$ l volume: $10 \mathrm{mM}$ Hepes ( $\mathrm{pH} 7.0)$, bovine serum albumen at $0.2 \mu \mathrm{g} / \mathrm{ml}, 10 \mathrm{mM} \mathrm{MgSO}{ }_{4}, 0.002 \%$ Triton X-100, 10 $\mathrm{mM} \mathrm{KCl}$, and the $10-\mu l$ volume of the PCR reaction. Digestions were performed at $45^{\circ} \mathrm{C}$ for $15 \mathrm{~min}$ and terminated by the addition of $5 \mu \mathrm{l}$ of $75 \mathrm{mM}$ EDTA ( $\mathrm{pH}$ 8.0) (Colbert et al. 2001). Reactions were frozen at $-20^{\circ} \mathrm{C}$ or held at $4^{\circ} \mathrm{C}$ briefly until purification.

\section{Detection of induced mutations.}

The CEL I-treated PCR fragments were purified using Sephadex G-50 medium columns in Whatman Unifilter 800 96-well spin plates (Whatman Inc., Clifton, NJ, U.S.A.). To prepare the columns, $750 \mu \mathrm{l}$ of water-hydrated Sephadex G-50 slurry was loaded into each well of the 96-well spin plate and spun at $750 \times g$ for $2 \mathrm{~min}$. The PCR reactions were loaded and spun 2 min at $750 \times g$ into a 96-well PCR plate containing a stop solution/loading dye $(37 \%$ [vol/vol] formamide, $4 \mathrm{mM}$ EDTA [pH 8.0], and bromophenol blue at $90 \mu \mathrm{g} / \mathrm{ml}$ ). The samples were heated uncovered but protected from light at $85^{\circ} \mathrm{C}$ for $45 \mathrm{~min}$ to reduce the volume prior to loading.

Approximately $1 \mu \mathrm{l}$ of the reduced product was loaded onto a 100-tooth paper comb (The Gel Company, San Francisco, U.S.A.) utilizing a comb loader (The Gel Company). The paper comb was loaded onto a denaturing $6 \%$ acrylamide gel $(25$ $\mathrm{cm})$ and electrophoresis performed at $1,500 \mathrm{~V}, 40 \mathrm{~mA}, 40 \mathrm{~W}$,

Table 2. Summary of induced changes for $P X T M-P L D^{\mathrm{a}}$

\begin{tabular}{|c|c|c|c|c|c|c|}
\hline Position $^{b}$ & Isolate & $\begin{array}{l}\text { Nucleotide } \\
\text { change }\end{array}$ & $\begin{array}{l}\text { Amino acid } \\
\text { change }\end{array}$ & Amino acid property changes ${ }^{c}$ & $\begin{array}{l}\text { Substitution } \\
\text { preferences }^{c}\end{array}$ & $\begin{array}{l}\text { Conserved in other } \\
\text { phospholipase Ds }\end{array}$ \\
\hline 2,319 & K1891 & $\mathrm{A} \rightarrow \mathrm{C}$ & L to $\mathrm{F}$ & Aliphatic to aromatic & Neutral & Yes \\
\hline 2,351 & K2883 & $\mathrm{C} \rightarrow \mathrm{T}$ & $\mathrm{P}$ to $\mathrm{L}$ & Changed to aliphatic and hydrophobic & Disfavored & No \\
\hline 2,410 & $\mathrm{~K} 2476$ & $\mathrm{~T} \rightarrow \mathrm{G}$ & $\mathrm{L}$ to $\mathrm{V}$ & Aliphatic to small aliphatic & Favored & $\begin{array}{l}\text { Valine in Phytophthora } \\
\text { infestans }\end{array}$ \\
\hline 2,558 & K2225 & $\mathrm{T} \rightarrow \mathrm{C}$ & $\mathrm{S}$ to $\mathrm{S}$ & NA & NA & NA \\
\hline 2,679 & K2675 & $\mathrm{C} \rightarrow \mathrm{T}$ & I to I & NA & NA & NA \\
\hline 2,685 & K2668 & $\mathrm{T} \rightarrow \mathrm{A}$ & $\mathrm{D}$ to $\mathrm{E}$ & Small negative charge to negative charge & Favored & Yes \\
\hline 2,745 & K2902 & $\mathrm{C} \rightarrow \mathrm{T}$ & $\mathrm{F}$ to $\mathrm{F}$ & NA & NA & NA \\
\hline 2,753 & K2239 & $\mathrm{T} \rightarrow \mathrm{C}$ & $\mathrm{V}$ to $\mathrm{A}$ & Aliphatic to nonaliphatic and very small & Neutral & Yes \\
\hline 2,893 & K2870 & $\mathrm{A} \rightarrow \mathrm{T}$ & $\mathrm{K}$ to stop & Polar to stop & NA & NA \\
\hline 2,900 & K2598 & $\mathrm{A} \rightarrow \mathrm{T}$ & $\mathrm{D}$ to $\mathrm{V}$ & $\begin{array}{l}\text { Polar to aliphatic; hydrophilic to hydrophobic and } \\
\text { charged to neutral }\end{array}$ & Disfavored & $\begin{array}{l}\text { Yes, only in } \\
\text { Phytophthora spp. }\end{array}$ \\
\hline 2,991 & K2005 & $\mathrm{G} \rightarrow \mathrm{A}$ & $\mathrm{G}$ to $\mathrm{E}$ & Aliphatic to polar and neutral to negative charge & Disfavored & No \\
\hline 3,070 & K2248 & $\mathrm{G} \rightarrow \mathrm{A}$ & $\mathrm{V}$ to I & Small aliphatic to aliphatic & Favored & No \\
\hline 3,083 & K1897 & $\mathrm{C} \rightarrow \mathrm{T}$ & $\mathrm{S}$ to $\mathrm{L}$ & Polar to aliphatic and hydrophilic to hydrophobic & Disfavored & No \\
\hline
\end{tabular}

a $\mathrm{NA}=$ not applicable.

${ }^{\mathrm{b}}$ Nucleotide position from the predicted start codon of Phytophthora sojae ID 130122 in the VBI microbial database.

c According to Betts and Russell (2003).

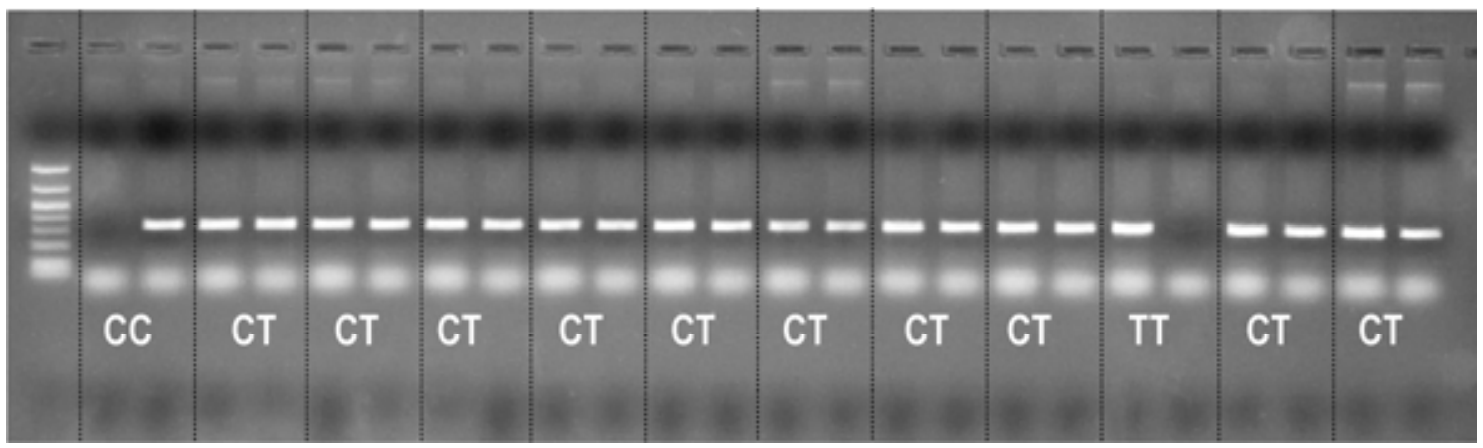

Fig. 6. SNP genotypes for 12 oospore progeny of Phytophthora sojae resolved using single-nucleotide-amplified polymorphism (SNAP) primers specific to either C (lanes 3, 5, 7, 9, 11, 13, 15, 17, 19, 21, 23, and 25) or T (lanes 2, 4, 6, 8, 10, 12, 14, 16, 18, 20, 22, and 24). The parent isolate was heterozygous for CT at a site in the P. sojae necrosis-inducing protein (PsojNIP) gene. Polymerase chain reaction products for the T- and C-specific primers from individual isolates are loaded in adjacent lanes from left to right (vertical lines separate individual isolates) and the resulting genotypes are specified. Lane $1=1-\mathrm{kb}$ ladder. 


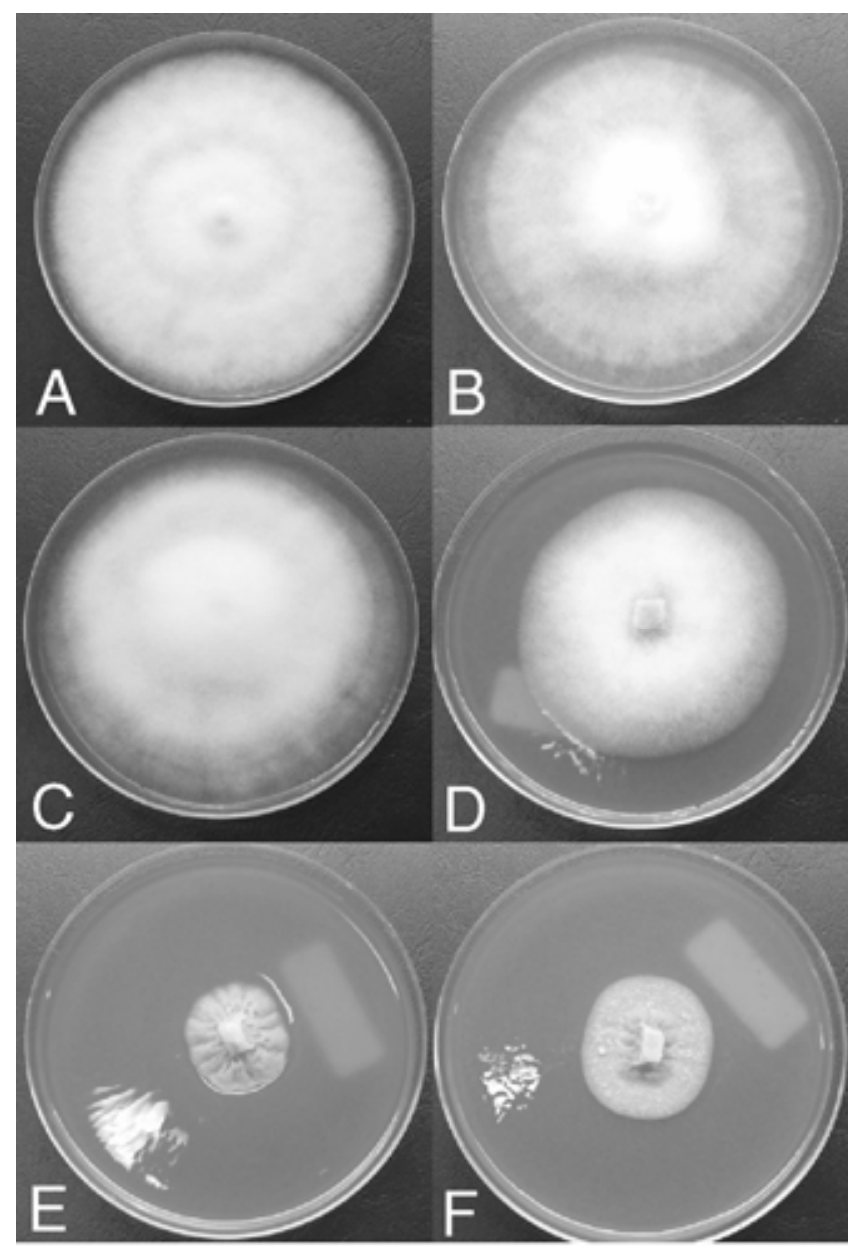

Fig. 7. Colony morphology of the wild-type Phytophthora sojae isolate P6497, and representatives of oospore progeny derived from the heterozygous mutant K2870 after 9 days of growth in the dark on full-strength V8 agar. A, P6497: wild type; B, LT2489: heterozygous (Wt/mt); C, LT2938 and D, LT2662: homozygous wild-type progeny (Wt/Wt); E, LT2506 and F, LT2501 homozygous mutant (mt/mt).

and $50^{\circ} \mathrm{C}$ in $1 \times$ Tris-borate EDTA buffer on a LI-COR 4300 DNA analysis system (LI-COR, Lincoln, NE, U.S.A.). Gels were run 3.0 to $3.5 \mathrm{~h}$. Following electrophoresis, TIFF images of the 700 and 800 channels were analyzed using Adobe Photoshop (version 8.0; Adobe Systems Inc., Seattle, WA, U.S.A.) and samples containing DNA fragments in addition to the wild-type PCR product were identified. The size of the additional bands in the 700 and 800 channels provides the approximate location of the SNP in the PCR fragment ( $\pm 20 \mathrm{bp}$ ) (Fig. 4). The PCR was repeated for mutants carrying induced mutations using unlabeled primers, and the PCR fragments were sequenced. The resulting traces were examined manually using Sequencher (version 4.1.4; Gene Codes Corp., Ann Arbor, MI, U.S.A.) and the presence of the induced change verified. Subsequently, the predicted impact on the coding sequence was assessed.

\section{Recovery of homozygous mutants.}

Mutants carrying amino-acid-changing mutations were recovered from long-term storage and grown on $60 \mathrm{~mm}$ of V8-PARP agar plates in the dark for 2 months. The mycelial mats on the surface of the plates was scraped off and homogenized thoroughly in $20 \mathrm{ml}$ of sterile water using a Tissue-tearor (Fisher Scientific Inc, Hampton, NH, U.S.A.) for $3 \mathrm{~min}$ at 30,000 rpm and filtered through one layer of sterile Kimwipe. The filtrate, containing a mixture of oospores and hyphal fragments, was treated with crude lysing enzymes from Trichoderma harzianum (Sigma-Aldrich Inc.) at $1 \mathrm{mg} / \mathrm{ml}$ for 16 to $20 \mathrm{~h}$ with gentle agitation and then diluted to $50 \mathrm{ml}$ with sterile water. The treated oospores were incubated under continuous fluorescent light and checked daily for the presence of germinating oospores. Germinating oospores were harvested using a modified Pasteur pipette as described previously (Lamour and Hausbeck 2000) and transferred to V8-PARP agar plates for growth.

The allelic state of each oospore progeny was tested using direct sequencing or allele-specific PCR. In the latter case, protocols and tools were used that are available on the Ausubel Laboratory web page to design SNAP primers specific to the wild-type and mutant alleles (SNAPER Program). The SNAP assay includes the intentional incorporation of a mismatched base at the $3^{\prime}$ end of an allele-specific forward primer three to four bases from the $3^{\prime}$ end of the primer. Two sets of primers, one for each of the alleles to be assayed, are utilized and, under the described PCR conditions, amplification occurs only in the presence of the correct allele (Drenkard et al. 2000). Four sets of reference and alternative allele primer pairs were tested for each SNP. Primer sets which provided unambiguous results for the reference (Ref. Forward Primer: ACAACGCACGCCT CCCGGTC and Ref. Reverse Primer: AGCGCCAGCGTTATC AACCACG) and the alternative (Alt. Forward Primer: ACAA CGCACGCCTCCCGGTT and Alt. Reverse Primer: AGCGC CAGCGTTATCAACCACG) allele at 28 cycles were chosen to screen the oospore progeny.

The SNAP protocol was modified for use in a SYBR Green real-time detection system. SYBR Green Master Mix (Applied Biosystems, Foster City, CA, U.S.A.) was substituted for the Taq polymerase, buffer, and nucleotides and the reactions were run on an ABI PRISM 7000 Sequence Detection System (Applied Biosystems) with the following program: $50^{\circ} \mathrm{C}$ for $2 \mathrm{~min}$, $94^{\circ} \mathrm{C}$ for $5 \mathrm{~min}$, and 28 cycles of $94^{\circ} \mathrm{C}$ for $30 \mathrm{~s}$ and $62^{\circ} \mathrm{C}$ for 1 $\min$. The $\mathrm{Ct}$ (cycle threshold) values for the reference and alternate primer pairs were used to score the oospore progeny alleles in place of agarose electrophoresis. An agarose gel with results from screening progeny for mutant isolate K1857 is shown in Figure 6.

\section{ACKNOWLEDGMENTS}

H. Meijer is financially supported by a grant from the Dutch Ministry of Agriculture, Nature, and Food Quality (LNV427). This material is based upon work supported by the National Science Foundation under grant no. 0347624 to K. Lamour and in part by the National Science Foundation Research Collaboration Networks in Biological Sciences program, grant no. EF-0130263. We wish to thank S. Henikoff, L. Comai, and B. Till at the Seattle Tilling Project for training on TILLING and M. Gijzen, D. Qutob, and B. Tyler for gene sequences and helpful advice as we developed gene targets. We also thank members of the Phytophthora Molecular Genetics Network for valuable suggestions and encouragement.

\section{LITERATURE CITED}

Ah Fong, A., and Judelson, H. S. 2003. Cell cycle regulator Cdc14 is expressed during sporulation but not hyphal growth in the fungus-like oomycete Phytophthora infestans. Mol. Microbiol. 50:487-494.

Baldauf, S. L. 2003. The deep roots of eukaryotes. Science 300:1703-1706.

Blanco, F. A., and Judelson, H. S. 2005. A bZIP transcription factor from Phytophthora interacts with a protein kinase and is required for zoospore motility and plant infection. Mol. Microbiol. 56:638-648.

Bottin, A., Larche, L., Villalba, F., Gaulin, E., Esquerre-Tugaye, M. T., and Rickauer, M. 1999. Green fluorescent protein (GFP) as gene expression reporter and vital marker for studying development and microbe-plant interaction in the tobacco pathogen Phytophthora parasitica var. nicotianae. FEMS (Fed. Eur. Microbiol. Soc.) Microbiol. Lett. 176:51-56.

Caldwell, D. G., McCallum, N., Shaw, P., Muehlbauer, G. J., Marshall, D. F., and Waugh, R. 2004. A structured mutant population for forward and reverse genetics in Barley (Hordeum vulgare L.). Plant J. 40:143-150. 
Colbert, T., Till, B. J., Tompa, R., Reynolds, S., Steine, M. N., Yeung, A. T., McCallum, C. M., Comai, L., and Henikoff, S. 2001. High-throughput screening for induced point mutations. Plant Physiol. 126:480-484.

Cvitanich, C., and Judelson, H. S. 2003. Stable transformation of the oomycete, Phytophthora infestans, using microprojectile bombardment. Curr. Genet. 42:228-235.

Dhonukshe, P., Laxalt, A. M., Goedhart, J., Gadella, T. W., and Munnik, T. 2003. Phospholipase D activation correlates with microtubule reorganization in living plant cells. Plant Cell 15:2666-2679.

Drenkard, E., Richter, B. G., Rozen, S., Stutius, L. M., Angell, N. A., Mindrinos, M., Cho, R. J., Oefner, P. J., Davis, R. W., and Ausubel, F. M. 2000. A simple procedure for the analysis of single nucleotide polymorphisms facilitates map-based cloning in Arabidopsis. Plant Physiol. 124:1483-1492.

Ella, K. M., Dolan, J. W., Qi, C., and Meier, K. E. 1996. Characterization of Saccharomyces cerevisiae deficient in expression of phospholipase D. Biochemistry J. 314:15-19.

Erwin, D. C., and Ribiero, O. K. 1996. Phytophthora Diseases Worldwide. The American Phytopathological Society, St. Paul, MN, U.S.A.

Forster, H., Tyler, B. M., and Coffey, M. D. 1994. Phytophthora sojae races have arisen by clonal evolution and by rare outcrosses. Mol. Plant-Microbe Interact. 7:780-791.

Gardiner, J. C., Harper, J. D., Weerakoon, N. D., Collings, D. A., Ritchie, S., Gilroy, S., Cyr, R. J., and Marc, J. 2001. A 90-kD phospholipase D from tobacco binds to microtubules and the plasma membrane. Plant Cell 13:2143-2158.

Gaulin, E., Jauneau, A., Villalba, F., Rickauer, M., Esquerre-Tugaye, M. T., and Bottin, A. 2002. The CBEL glycoprotein of Phytophthora parasitica var. nicotianae is involved in cell wall deposition and adhesion to cellulosic substrates. J. Cell Sci. 115:4565-4575.

Gijzen, M., and Nurnberger, T. 2006. Nep1-like proteins from plant pathogens: Recruitment and diversification of the NPP1 domain across taxa. Phytochemistry. 67:1800-1807.

Henikoff, S., and Comai, L. 2003. Single-nucleotide mutations for plant functional genomics. Annu. Rev. Plant Biol. 54:375-401.

Jiang, R. H., Tyler, B. M., Whisson, S. C., Hardham, A. R., and Govers, F. 2006. Ancient origin of elicitin gene clusters in Phytophthora genomes. Mol. Biol. Evol. 23:338-351

Judelson, H. S., Coffey, M. D., Arredondo, F. R., and Tyler, B. M. 1993. Transformation of the oomycete pathogen Phytophthora megasperma $\mathrm{f}$. sp. glycinea occurs by DNA integration into single or multiple chromosomes. Curr. Genet. 23:211-218.

Judelson, H. S., and Michelmore, R. W. 1991. Transient expression of foreign genes in the oomycete Phytophthora infestans using Bremia lactucae regulatory sequences. Curr. Genet. 19:453-459.

Kamoun, S., van West, P., Vleeshouwers, V. G., de Groot, K. E., and Govers, F. 1998. Resistance of Nicotiana benthamiana to Phytophthora infestans is mediated by the recognition of the elicitor protein INF1. Plant Cell 10:1413-1426.

Keeling, P. J., Burger, G., Durnford, D. G., Lang, B. F., Lee, R. W. Pearlman, R. E., Roger, A. J., and Gray, M. W. 2005. The tree of eukaryotes. Trends Ecol. Evol. 20:670-676.

Lamour, K., and Finley, L. 2006. A strategy for recovering high quality genomic DNA from a large number of Phytophthora isolates. Mycologia 98:515-518

Lamour, K. H., and Hausbeck, M. K. 2000. Mefenoxam insensitivity and the sexual stage of Phytophthora capsici in Michigan cucurbit fields. Phytopathology 90:396-400.

Latijnhouwers, M., and Govers, F. 2003. A Phytophthora infestans G-protein beta subunit is involved in sporangium formation. Eukaryot. Cell 2:971-977.

Latijnhouwers, M., Ligterink, W., Vleeshouwers, V. G., van West, P., and Govers, F. 2004. A G $\alpha$ subunit controls zoospore motility and virulence in the potato late blight pathogen Phytophthora infestans. Mol. Microbiol. 51:925-936.

McCallum, C. M., Comai, L., Greene, E. A., and Henikoff, S. 2000. Targeting induced local lesions IN genomes (TILLING) for plant functional genomics. Plant Physiol. 123:439-442.

Meijer, H. J. G., Latijnhouwers, M., Ligterink, W., and Govers, F. 2005. A transmembrane phospholipase D in Phytophthora; a novel PLD subfamily. Gene 350:173-182.

Morris, P. F., Bone, E., and Tyler, B. M. 1998. Chemotropic and contact responses of Phytophthora sojae hyphae to soybean isoflavonoids and artificial substrates. Plant Physiol. 117:1171-1178.

Morris, P. F., and Ward, E. W. B. 1992. Chemoattraction of zoospores of the soybean pathogen, Phytophthora sojae, by isoflavones. Phys. Mol. Plant Pathol. 40:17-22.
Moy, P., Qutob, D., Chapman, B. P., Atkinson, I., and Gijzen, M. 2004. Patterns of gene expression upon infection of soybean plants by Phytophthora sojae. Mol. Plant-Microbe Interact. 17:1051-1062.

Oleykowski, C. A., Bronson Mullins, C. R., Godwin, A. K., and Yeung, A. T. 1998. Mutation detection using a novel plant endonuclease. Nucleic Acids Res. 26:4597-4602.

Perry, J. A., Wang, T. L., Welham, T. J., Gardner, S., Pike, J. M., Yoshida, S., and Parniske, M. 2003. A TILLING reverse genetics tool and a webaccessible collection of mutants of the legume Lotus japonicus. Plant Physiol. 131:866-871.

Qutob, D., Kamoun, S., and Gijzen, M. 2002. Expression of a Phytophthora sojae necrosis-inducing protein occurs during transition from biotrophy to necrotrophy. Plant J. 32:361-373.

Rudge, S. A., Morris, A. J., and Engebrecht, J. 1998. Relocalization of phospholipase D activity mediates membrane formation during meiosis. J. Cell Biol. 140:81-90.

Till, B. J., Reynolds, S. H., Greene, E. A., Codomo, C. A., Enns, L. C., Johnson, J. E., Burtner, C., Odden, A. R., Young, K., Taylor, N. E., Henikoff, J. G., Comai, L., and Henikoff, S. 2003. Large-scale discovery of induced point mutations with high-throughput TILLING. Genome Res. 13:524-530.

Tyler, B. M., Tripathy, S., Zhang, X., Dehal, P., Jiang, R. H. Y., Aerts, A., Arredondo, F., Baxter, L., Bensasson, D., Beynon, J. L., Damasceno, C. M. B., Dickerman, A., Dorrance, A. E., Dou, D., Dubchak, I., Garbelotto, M., Gijzen, M., Gordon, S., Govers, F., Grunwald, N. J., Huang, W., Ivors, K., Jones, R. W., Kamoun, S., Krampis, K., Lamour, K., Lee, M.K., McDonald, W. H., Medina, M., Meijer, H. J. G., Nordberg, E., Maclean, D. J., Ospina-Giraldo, M. D., Morris, P. F., Phuntumart, V. Putnam, N., Rash, S., Rose, J. K. C., Sakihama, Y., Salamov, A., Savidor, A., Scheuring, C., Smith, B., Sobral, B. W. S., Terry, A., TortoAlalibo, T., Win, J., Xu, Z., Zhang, H., Grigoriev, I., Rokhsar, D., and Boore, J. 2006. Phytophthora genome sequences uncover evolutionary origins and mechanisms of pathogenesis. Science. 313:1261-1266.

van West, P., de Jong, A. J., Judelson, H. S., Emons, A. M., and Govers, F. 1998. The ipiO gene of Phytophthora infestans is highly expressed in invading hyphae during infection. Fungal Genet. Biol. 23:126-138.

van West, P., Reid, B., Campbell, T. A., Sandrock, R. W., Fry, W. E. Kamoun, S., and Gow, N. A. 1999. Green fluorescent protein (GFP) as a reporter gene for the plant pathogenic oomycete Phytophthora palmivora. FEMS (Fed. Eur. Microbiol. Soc.) Microbiol. Lett. 178:71-80.

Vijn, I., and Govers, F. 2003. Agrobacterium tumefaciens mediated transformation of the oomycete plant pathogen Phytophthora infestans. Mol. Plant Pathol. 4:459-468.

Waksman, M., Eli, Y., Liscovitch, M., and Gerst, J. E. 1996. Identification and characterization of a gene encoding phospholipase D activity in yeast. J. Biol. Chem. 271:2361-2364

Weiland, J. J. 2003. Transformation of Pythium aphanidermatum to geneticin resistance. Curr. Genet. 42:344-352.

Whisson, S. C., Avrova, A. O., van West, P., and Jones, J. T. 2005. A method for double-stranded RNA-mediated transient gene silencing in Phytophthora infestans. Mol. Plant Pathol. 6:153-163.

Wienholds, E., van Eeden, F., Kosters, M., Mudde, J., Plasterk, R. H., and Cuppen, E. 2003. Efficient target-selected mutagenesis in zebrafish. Genome Res. 13:2700-2707.

Winkler, S., Schwabedissen, A., Backasch, D., Bokel, C., Seidel, C. Bonisch, S., Furthauer, M., Kuhrs, A., Cobreros, L., Brand, M., and Gonzalez-Gaitan, M. 2005. Target-selected mutant screen by TILLING in Drosophila. Genome Res. 15:718-723.

Yang, B., Wen, X., Kodali, N. S., Oleykowski, C. A., Miller, C. G., Kulinski, J., Besack, D., Yeung, J. A., Kowalski, D., and Yeung, A. T. 2000. Purification, cloning, and characterization of the CEL I nuclease. Biochem. J. 39:3533-3541.

Zouwail, S., Pettitt, T. R., Dove, S. K., Chibalina, M. V., Powner, D. J., Haynes, L., Wakelam, M. J., and Insall, R. H. 2005. Phospholipase D activity is essential for actin localization and actin-based motility in Dictyostelium. Biochem. J. 389:207-214.

\section{AUTHOR-RECOMMENDED INTERNET RESOURCES}

CODDLE primer design website: http://www.proweb.org/input/ Massachusetts General Hospital Department of Molecular Biology, Ausubel Lab's SNAPER website: genetics.mgh.harvard.edu/ausubelweb/

Seattle TILLING Project website: tilling.fhcrc.org:9366/

VBI Microbial Database

Virgnia Bioinformatics Institute VBI Microbial database: phytophthora.vbi.vt.edu 